\title{
Metode Memperpanjang Masa Simpan Minuman Sari Markisa Dengan Menggunakan Mesin Multifungsi di Kampung Ramqisa
}

\author{
Dwi Ana Anggorowati ${ }^{1}$, Nanik AR ${ }^{2}$, Maranatha $W^{3}$, Dimas Indra \\ Laksmana $^{4 *}$ \\ 1,2 Teknik Kimia, Fakultas Teknologi Industri, Institut Teknologi Nasional Malang \\ ${ }^{3}$ Teknik Sipil, Progam Pascasajana, Institut Teknologi Nasional Malang \\ ${ }^{4}$ Teknik Industri, Progam Pascasajana, Institut Teknologi Nasional Malang \\ Email: sengkaling142@gmail.com \\ *Corresponding author: Dimas Indra Laksmana
}

\begin{abstract}
ABSTRAK
Pertanian di perkotaan yang berlokasi di Kelurahan Rampal Celaket Kecamatan Klojen Kota Malang di wilayah RW I menjadi salah satu lokasi percontohan dimana masyarakat dilingkungan tersebut benar-benar memanfaatkan lahan pekarangan untuk bercocok tanam. Berbagai tanaman sayur dan buah-buahan dibudidayakan dilokasi ini untuk dijadikan produk olahan yang dikomersialkan sehingga bisa menjadi produk unggulan di kampung ramqisa. Dalam memproduksi minuman sari markisa, kendala terbesarnya adalah produk sangat mudah rusak. Kendala ini disebabkan karena mitra tidak memahami bagaimana penanganan produksi dengan baik. Untuk mengatasi hal ini, tim pendamping dari ITN Malang membantu mitra dalam menangani proses pembuatannya, diantaranya adalah memberikan penyuluhan atau pelatihan dalam memproduksi minuman jus markisa. Selain itu, tim membantu dalam hal mengupayakan mesin produksi dengan cara membantu mendesain mesin yang sesuai dengan proses terkontrol. Mesin tersebut adalah Mesin Pemanas dan Pengaduk dan pengemas didesain mampu mengendalikan mikroorganisme penyebab pembusukan dari sari buah markisa dengan cara mengontrol suhu pemasakan, sehingga proses sterilisasi sari buah dapat dicapai. Dalam desain mesin ini, juga dibuat mampu untuk melakukan pengadukan sehingga jus buah tidak terpisah dan jus buah tercampur homogen. Dengan alat multifungsi mampu membuat 20 Liter minuman sari markisa dengan waktu 1 jam/1 tenaga kerja, jadi lebih bisa menghemat waktu jika dibandingkan denga metode lama yang membutuhkan waktu 3 jam/2 tenaga kerja, Masa Simpan : penyimpanan di lemari es bertahan 3 bulan, dan di suhu ruang 1 bulan lebih bagus dari produk sebelumya yaitu penyimpanan di lemari es bertahan 10 hari dan disuhu ruang 2 hari.
\end{abstract}

Kata Kunci: jus markisa; mesin pemanas dan pengaduk; sterilisasi.

\section{ABSTRACT}

Agriculture in urban areas located in Rampal Celaket Subdistrict, Klojen Subdistrict, Malang City in RW I region is one of the pilot locations where the community actually uses the yard to grow crops. Various vegetable and fruit plants are cultivated in this location to be processed products that are commercialized so that they can become superior products in Ramqisa village. In producing passion fruit drinks, the biggest obstacle is that the products are very perishable. This obstacle is caused because the partners do not understand how to handle production properly. To overcome this, a team of assistants from ITN Malang helps partners in handling the manufacturing process, including providing counseling or training in producing passion fruit juice drinks. In addition, the team helped in terms of working on a production machine by helping to design machines that are in accordance with controlled processes. The machine is a heating and stirring machine and the packaging is designed to be able to control the microorganisms that cause decomposition of passion fruit juice by controlling the cooking temperature, so that the sterilization 
process of fruit juice can be achieved. In the design of this machine, it is also made capable of stirring so that the fruit juice is not separated and the fruit juice is mixed homogeneously. With a multifunctional tool capable of making 20 Liters of passion fruit drinks with an hour / 1 of labor, so it can save more time when compared with the old method which takes 3 hours / 2 of labor, Save Period: storage in the refrigerator lasts 3 months, and at room temperature 1 month better than the previous product that is storage in the refrigerator last 10 days and at room temperature 2 days.

Keywords: heating and stirring machines; passion fruit juice; sterilization.

\section{PENDAHULUAN}

Pembangunan pertanian pada hakekatnya adalah upaya untuk memperdayakan masyarakat agar meningkat kesejahteraannya, sekaligus diharapkan meningkat pula kemandiriannya. Pertanian di perkotaan tidak memungkinkan menghasilkan produksi tanaman pangan karena terbatasnya lahan yang dimiliki. Sehubungan dengan hal itu kegiatan pertanian di perkotaan lebih cocok untuk memanfaatkan lahan pekarangan dengan bercocok tanam atau pengolahan hasil pertanian pasca panen. Berawal dari kepedulian warga RW. I Kelurahan Rampal Celaket Kota Malang yang tinggi terhadap lingkungan dan demi terwujudnya kerukunan dan kebersamaan warga serta keinginan berbudidaya tanaman sayur dan buah serta meningkatkan keterampilan dalam pengolahan hasil pertanian sebagai produk unggulan, dibuatlah suatu kesepakatan membentuk Kader Lingkungan di wilayah RW. I Kelurahan Rampal Celaket Kecamatan Klojen Kota Malang.

Kader lingkungan RW. I ikut mengembangkan kepedulian dan peran serta masyarakat terhadap pelestarian lingkungan, dengan melakukan usaha: 1) Penghijauan yang meliputi: pengadaan dan penanaman tanaman pelindung/hias, tanaman toga dan taman toga, budidaya tanaman sayur organik dan pembibitan dengan memanfaatkan setiap lahan yang ada di lingkungan tempat tinggal masing-masing; 2) Mengolah dan memanfaatkan (daur ulang) sampah basah dan kering; 3) Membuat produk unggulan dan meningkatkan nilai ekonomis dari produk daur ulang agar dapat meningkatkan kesejahteraan warga baik dari sisi ekonomi maupun sosialbudaya. Salah satu produk olahan unggulan adalah berupa juss markisa dalam kemasan, hasil panen buah markisa setiap $1,5 \mathrm{~kg}$ setelah diproses dengan air matang dan gula pasir menghasilkan kurang lebih 20 liter juss markisa. Sehingga dihasilkan kurang lebih 50 botol plastik juss markisa@330 ml atau kurang lebih 80 gelas dengan ukuran $200 \mathrm{ml}$ juss markisa. Target pasar produk juss markisa adalah by order (pesanan).

Kendala terbesar mitra saat ini adalah produk unggulannya juss markisa sangat mudah rusak, mitra tidak memahami bagaimana penanganan pasca panen. Masa simpan dari minuman sari markisa sangat singkat apabila tidak dimasukkan dalam lemari pendingin. Sehingga perlu diupayakan perbaikan dalam proses pembuatan minuman 
sari markisa dan merancang alat dan memperbaiki tahapan proses produksi.
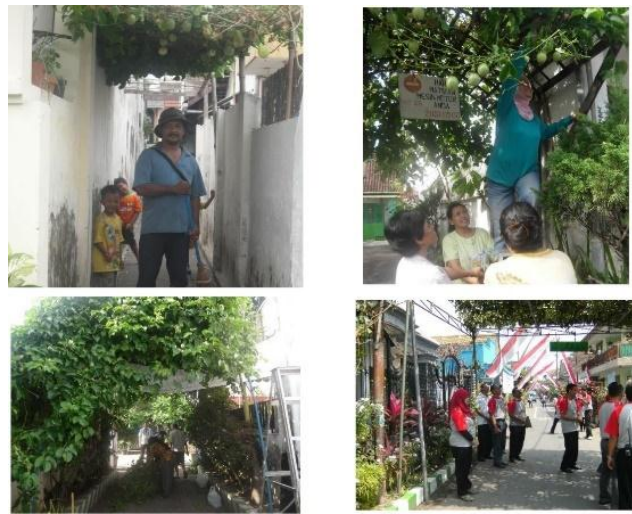

Gambar 1. Pemanfaatan Lahan Sebagai Budidaya Tanaman

\section{METODE PENELITIAN}

Menyadari adanya potensi permasalahan Kelompok Kader Lingkungan warga RW. I Kelurahan Rampal Celaket Kota Malang maka dipandang perlu untuk mengadakan kegiatan yang menunjang program ini yaitu untuk menangani berbagai permasalahan yang ada. Kegiatan tersebut antara lain memberikan Penyuluhan, Perancangan dan Pembuatan Mesin untuk pembuatan minuman sari markisa.

Tahapan pembuatan minuman sari Markisa selama ini masih manual dan memerlukan beberapa tahapan proses. Dengan adanya alat tersebut maka ada beberapa tahapan proses yang bisa dipersingkat untuk mengurangi kontaminasi. Oleh karena perlu identifikasi permasalahan sesuai tahapan berikut.

1. Kebutuhan

Membuat Mesin multifungsi yang bisa berfungsi sebagai pemanas (terkontrol), pengaduk dan filler.

2. Analisa Masalah

Masa simpan dari minuman sari markisa sangat singkat dikarenakan pembuatannya masih sederhana dengan tahapan proses yang msih panjang, sehingga kurang effisien.

3. Rumusan Masalah

Bagaimana merancang dan membuat mesin untuk memproduksi sari markisa agar diperoleh tahapan yang singkat dan lebih effisien?

4. Konsep Desain

a. Mesin tersebut harus mempunyai kontrol suhu yang bisa disetting pada kisaran 70100OC.

b. Bahan terbuat dari Stainless steel untuk menghindari korosi.

c. Bejana mempunyai alat pengaduk yang digunakan untuk pencampuran gula, sari markisa dan air.

d. Kondisi bejana fleksibel bisa dalam kondisi terbuka dan tertutup.

e. Ada kran pengeluaran untuk filler didalam wadah kemasan.

f. Perawatan dan perbaikan alat relatif mudah.

5. Membuat Mesin multi fungsi untuk produksi minuman sari markisa

6. Uji Coba Mesin

Uji coba pertama dilakukan saat berada di Lokasi Mitra yaitu di 
RW. I Kelurahan Rampal

Celaket Kota Malang

7. Evaluasi

8. Rekomendasi Mitra.

\section{HASIL DAN PEMBAHASAN}

Pelaksanaan

kegiatan pengabdian kepada masyarakat sebagai upaya untuk membantu meningkatkan kualitas dan kuantitas produksi minuman sari markisa diharapkan dapat menjadi produk unggulan dan meningkatkan pendapatan warga RW 1 Kelurahan Rampal Celaket Kota Malang. Pengabdian ini dilakukan oleh tim Pengabdian Masyarakat ITN Malang. Mesin mesin multifungsi untuk memproduksi minuman sari markisa secara garis besar terdiri dari 3 fungsi yaitu pemanas, pengaduk dan pengisi (filler). Mesin multifungsi untuk memproduksi minuman sari markisa mempunyai spesifikasi sebagai berikut.

1. Kapasitas : 25 Liter

2. Penggerak : $0,25 \mathrm{HP}$

3. Ukuran Mesin : $\mathrm{P}=55 ; \mathrm{L}=35 ; \mathrm{T}$ $=100$

4. Pemanas : Kompor Mawar

5. Termokopel : Digital

6. Frame : Stainless Steel pipa $2 \times 4$

7. Dinding : Plat MS /Mild Steel

8. Lain-lain : Transmisi

9. Hasil : (Standart sesuai panas yang ditentukan kisaran 70$\left.100^{\circ} \mathrm{C}\right)$.

Dengan menggunakan alat multi fungsi pada proses pembuatan minuman sari markisa, suhu pemanasan bisa dikontrol pada temperatur $70 \mathrm{oC}$ sehingga vitamin $\mathrm{C}$

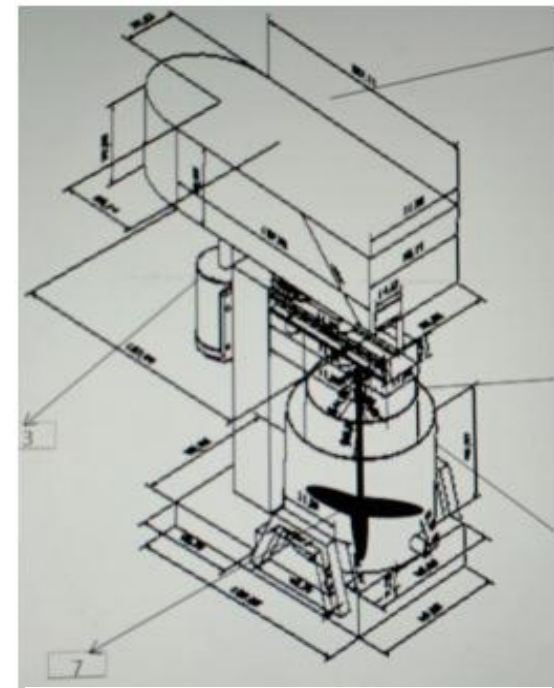

Gambar 2. Rancangan Mesin

dan kadar antioksidan-nya tidak rusak. Proses pemanasan dan dengan proses masak yang benar ternyata bisa menambah masa simpan dari produk tersebut ditandai dengan tidak adanya mikroba E. Coli dan hal tersebut bisa digunakan sebagai indikator bahwa minuman tersebut layak dikonsumsi dan higyenis. Dengan alat multifungsi mampu membuat 20 Liter minuman sari markisa dengan waktu 1 jam/1 tenaga kerja, jadi lebih bisa menghemat waktu jika dibandingkan denga metode lama yang membutuhkan waktu 3 jam/2 tenaga kerja, Masa Simpan : penyimpanan di lemari es bertahan 3 bulan, dan di suhu ruang 1 bulan lebih bagus dari produk sebelumya yaitu penyimpanan di lemari es bertahan 10 hari, dan di suhu ruang 2 hari, Analisa Vitamin C 5,62mg/100 mg, proses dengan mesin tidak memerlukan wadah yang banyak cukup didalam 1 bejana bisa sampai proses pengemasan. 


\section{SIMPULAN}

Dari hasil kegiatan pengabdian kepada masyarakat yang telah dilaksanakan tim IbM ITN Malang dapat disimpulkan bahwa dengan memperkenalkan teknologi tepat guna mesin mesin multifungsi untuk memproduksi minuman sari markisa pada masyarakat dalam hal ini para Kader Lingkungan RW. I Kelurahan Rampal Celaket Kota Malang, diharapkan dapat mengembangkan pengetahuan dan pemahaman kepada para kader atau mitra tentang proses pembuatan minuman sari markisa dan teknologi sederhana mesin multifungsi. Dengan diterapkannya mesin multifungsi untuk memproduksi minuman sari markisa maka akan meningkatkan produksi minuman sari markisa baik secara kualitas maupun kuantitas.

Dengan alat multifungsi mampu membuat 20 Liter minuman sari markisa dengan waktu 1 jam/1 tenaga kerja, menghemat waktu jika dibandingkan denga metode lama yang membutuhkan waktu $3 \mathrm{jam} / 2$ tenaga kerja; Masa Simpan: penyimpanan di lemari es bertahan 3 bulan; dan disuhu ruang 1 bulan lebih baik dari produk sebelumya yaitu penyimpanan di lemari es bertahan 10 hari; dan disuhu ruang 2 hari.

\section{DAFTAR PUSTAKA}

Hutabarat, Julianus and Setyawati, Harimbi and Anggorowati, Dwi Ana (2016) Penerapan Mesin Pengolahan Kompos Untuk Peningkatan Hasil Produksi Kompos Organik Pada Urban Farm Kelurahan Rampal Celaket Kota Malang. INDUSTRI INOVATIF, 6 (2). pp. 6-9.
Desrosier, N. W. 1983. Food Preservation. The New Encyclopedia British Macropedia Vol. 7.

Fardiaz, S. 1992. Mikrobiologi Pengolahan Pangan Lanjut. PAU Pangan dan Gizi IPB. Bogor.

Frazier W.C., dan D.C. Westhoff. 1978. Food Microbiology. Mc Graw-Hill Book Co. Inc. New York.

Jongen, W. 2002. Fruits and Vegetable Processing. Woodhead Publishing Limited, Cambridge. England.

Woodroof, J. G. 1979. Coconuts; Production and Processing, Products. The AVI Publishing Company, Inc., Westport, Connecticut.

Desrosier, N. W. 1983. Food Preservation. New Encyclopedia British Macropedia vol. 7.

Karsinah, F.H. Silalahi dan A. Manshur, 2007. Eksplorasi dan Karakterisasi Plsma Nutfah Tanaman Markisa.

Karsinah, 2010. Markisa Asam (Passifloraedulis Sims) Buah Eksotis Kaya Manfaat. Pusat Penelitian dan Pengembangan Hortikultura.Badan Litbang Pertanian. Jakarta.

Verheij, E.W.M dan R.E. Cornel. 1997. Buah-buahan Yang Dapat Dimakan. Gramedia Pustaka Utama. Jakarta. 